This item was submitted to Loughborough's Research Repository by the author.

Items in Figshare are protected by copyright, with all rights reserved, unless otherwise indicated.

\title{
Changes in work affect in response to lunchtime walking in previously physically inactive employees: a randomized trial
}

PLEASE CITE THE PUBLISHED VERSION

http://dx.doi.org/10.1111/sms.12398

\section{PUBLISHER}

(c) Wiley

\section{VERSION}

AM (Accepted Manuscript)

\section{PUBLISHER STATEMENT}

This work is made available according to the conditions of the Creative Commons Attribution-NonCommercialNoDerivatives 4.0 International (CC BY-NC-ND 4.0) licence. Full details of this licence are available at: https://creativecommons.org/licenses/by-nc-nd/4.0/

\section{LICENCE}

CC BY-NC-ND 4.0

\section{REPOSITORY RECORD}

Thogersen-Ntoumani, Cecilie, Elizabeth A. Loughren, Florence-Emilie Kinnafick, lan M. Taylor, Joan L. Duda, and Kenneth R. Fox. 2019. "Changes in Work Affect in Response to Lunchtime Walking in Previously Physically Inactive Employees: A Randomized Trial”. figshare. https://hdl.handle.net/2134/17145. 


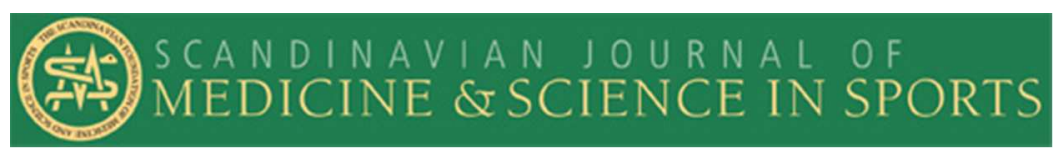

\section{Changes in Work Affect in Response to Lunchtime Walking in Previously Physically Inactive Employees: A Randomised Trial}

\begin{tabular}{|r|l|}
\hline Journal: & Scandinavian Journal of Medicine and Science in Sports \\
\hline Manuscript ID: & SJMSS-O-682-14.R1 \\
\hline Manuscript Type: & Original Article \\
\hline Complete List of Authors: & $\begin{array}{l}\text { Thogersen-Ntoumani, Cecilie; Curtin University, School of Psychology \& } \\
\text { Speech Pathology } \\
\text { Loughren, Elizabeth; University of Gloucestershire, School of Sport and } \\
\text { Exercise } \\
\text { Kinnafick, Florence-Emilie; University of Northampton, School of Health } \\
\text { Taylor, Ian; Loughborough University, School of Sport, Exercise \& Health } \\
\text { Sciences } \\
\text { Duda, Joan; The /university of Birmingham, School of Sport and Exercise } \\
\text { Sciences } \\
\text { Fox, Kenneth; The /university of Birmingham, School of Sport and Exercise } \\
\text { Sciences }\end{array}$ \\
\hline Keywords: & $\begin{array}{l}\text { well-being, physical activity, intervention, Ecological Momentary } \\
\text { Assessment, workplace, United Kingdom }\end{array}$ \\
\hline
\end{tabular}

\section{SCHOLARONE ${ }^{m}$}

Manuscripts 
Running head: AFFECTIVE CHANGES IN INACTIVE EMPLOYEES

1 Changes in Work Affect in Response to Lunchtime Walking in Previously Physically Inactive

2 Employees: A Randomised Trial

3

4 Cecilie Thøgersen-Ntoumani ${ }^{1 *}$, Elizabeth A. Loughren ${ }^{2}$, Florence-Emilie Kinnafick ${ }^{3}$, Ian M

5 Taylor ${ }^{4}$ Joan L. Duda ${ }^{5}, \&$ Kenneth R. Fox ${ }^{5}$

6

7

$8{ }^{1}$ School of Psychology \& Speech Pathology, Curtin University, GPO Box U1987, Perth,

$9 \quad$ Western Australia 6845, Australia

$10 \quad{ }^{2}$ School of Sport and Exercise, University of Gloucestershire, Gloucester, GL2 9HW, United

11 Kingdom

$12{ }^{3}$ School of Health, University of Northampton, Northampton, NN2 7AL, United Kingdom

$13{ }^{4}$ School of Sport, Exercise and Health Sciences, Loughborough University, Loughborough

14 LE11 3TU, UK

$15{ }^{5}$ School of Sport, Exercise, \& Rehabilitation Sciences, University of Birmingham, Edgbaston, 16 Birmingham, B15 2TT, United Kingdom

17

$18 *$ Corresponding author

19 Email address:

20 C.Thogersen@curtin.edu.au

21 Phone: +61892665171

22 Fax: +61892662464

23

24 


\section{Running head: AFFECTIVE CHANGES IN INACTIVE EMPLOYEES}

1 Changes in Work Affect in Response to Lunchtime Walking in Previously Physically Inactive

2 Employees: A Randomised Trial

3

\section{Abstract}

4 Background: Physical activity may regulate affective experiences at work, but controlled

5 studies are needed and there has been a reliance on retrospective accounts of experience. The

6 purpose of the present study was to examine the effect of lunchtime walks on momentary

7 work affect at the individual and group level. Methods: Physically inactive employees $(N=$

$856 ; M$ age $=47.68 ; 92.86 \%$ female) from a large University in the UK were randomised to

9 immediate (IT) or delayed treatment (DT). The DT participants completed both a control and

10 intervention period. During the intervention period participants partook in three weekly 30 -

11 minute lunchtime group-led walks for 10 weeks. They completed twice daily affective reports

12 at work (morning and afternoon) using mobile phones on two randomly chosen days per

13 week. Multilevel modelling was used to analyse the data. Results: Lunchtime walks improved

14 enthusiasm, relaxation and nervousness at work, although the pattern of results differed

15 depending on whether between-group or within-person analyses were conducted.

16 Conclusions: The intervention was effective in changing some affective states and may have

17 broader implications for public health and workplace performance.

Key words: well-being, physical activity, intervention, Ecological Momentary

20 Assessment, workplace, United Kingdom 
Running head: AFFECTIVE CHANGES IN INACTIVE EMPLOYEES

There is strong causal evidence linking physical inactivity with non-communicable

2 diseases and mortality (Lee et al., 2012). The evidence base linking physical inactivity with

3 mental illness, and physical activity with mental health and well-being, is also accumulating

4 (e.g., Penedo \& Dahn, 2005). For example, synthesizing the literature on the acute effects of exercise on energy in healthy populations, Loy, O’Connor and Dishman (2013) found a and Buck (2009) reported increases in high activation positive affect (e.g., energy) from even low to moderate intensity exercise training over 10-12 weeks (Cohen's $d=.47$ ), with those with low energy scores at baseline showing larger effects (Cohen's $d=.63$ ). Physical activity

consistently positive effect of (mainly low-to-moderate intensity) exercise on energy levels, although no consistent effect of acute bouts of exercise on fatigue. Another meta-analysis conducted by Puetz, O’Connor and Dishman (2006) reported a moderate effect of physical activity on increases in energy and reductions in fatigue, although $77 \%$ of the effects were based on studies conducted with patient samples. Similarly, Reed and Ones (2006) and Reed may change affective experiences in different spheres of life, such as work. Indeed, according to Hecht and Boies (2009) physical activity may work to recover cognitive and affective resources (such as concentration and energy) that have been depleted during the course of work, and research in the non-work domain has supported the propensity of physical activity in regulating affect (Thayer et al., 1994). The purpose of the present study was to examine the effects of a physical activity intervention on daily changes in work-related well-being in University employees who were initially physically inactive.

\section{The Role of Physical Activity in Employee Health and Well-Being}

Physical activity can serve as an important driver of employee health and well-being among physically inactive employees. Some evidence suggests that physically inactive employees can be recruited to, adhere to, and benefit from, participation in walking programmes (Authors, in press). Increases in step counts, reductions in Body Mass Index 
Running head: AFFECTIVE CHANGES IN INACTIVE EMPLOYEES

1 (BMI), waist girths, systolic blood pressure and resting heart rates have been reported as a

2 result of workplace walking interventions (Chan et al., 2004; Dugdill et al., 2008; Gilson et

3 al., 2007). Brown et al. (2011) have recently documented the effects of physical activity

4 interventions on workplace (e.g., job satisfaction, productivity), psychosocial (e.g., anxiety,

5 depression, and other dimensions of affect) and physical (e.g., general health, fatigue,

6 physical functioning) well-being in employees.

7 There is some evidence from previous research that employees experience greater well-

8 being on physically active days than on inactive days. An observational study by Coulson et

9 al. (2008) with 201 office-based employees showed that on exercise days (but not on non-

10 exercise days), positive affect and feelings of tranquility increased, while negative affect

11 decreased throughout the working day.

12 The Use of Ecological Momentary Assessment (EMA) in Physical Activity and Well-

13 Being Research

14 Most work examining the relationship between physical activity and mental well-

15 being has relied on retrospective accounts of experience. This is problematic due to potential

16 memory distortions. Indeed, individuals tend to have trouble recalling the intensity and

17 frequency of particular affective states (Thomas \& Diener, 1990). EMA, also referred to as

18 the experience sampling method, allows for the examination of daily contextual effects on

19 affect that is measured in real time (Hektner et al, 2007). Some recent studies adopted

20 momentary assessment techniques to examine the dynamic associations between physical

21 activity and affect in general samples of adult populations which are relevant to the present

22 study. Such studies have demonstrated increases in positive affect (such as valence, energetic

23 arousal and calmness) following bouts of physical activity (Kanning \& Schlicht, 2010;

24 Wichers et al., 2011), which, in one study, were sustained up to three hours following the

25 physical activity bout (Wichers et al., 2011). With regard to negative affect, studies with 
Running head: AFFECTIVE CHANGES IN INACTIVE EMPLOYEES

1 healthy adults have shown mixed effects (Gauvin, Rejeski, \& Norris, 1996; Kanning \&

2 Schlicht, 2010; Wichers et al., 2011; Giacobbi et al., 2005; Ready et al., 2009)

3 The extant research reviewed above is characterised by some important limitations.

4 First, the studies all employed observational designs for which causality cannot be inferred.

5 Second, previous studies have used participants who were regular exercisers prior to the

6 beginning of the studies. This means that the potential public health impact of the results is

7 limited in that the results cannot be generalised to physically inactive employees who are at

8 greater risk of ill health. Third, all studies have relied on self-report questionnaires to measure

9 physical activity. Fourth, researchers have not examined the dynamic associations between

10 physical activity and fatigue despite the relevance of fatigue to employee well-being

11 (Salanova, Del Libano, Llorens, \& Schaufeli, 2014) and work performance (Samkoff \&

12 Jacques, 1991). Finally, EMA based studies examining the relation between physical activity

13 and affective states have not used work-related measures.

14 To our knowledge, the present study represents the first attempt to address these

15 limitations. Thus, the present study employed a randomised controlled design with physically

16 inactive adults to examine the causal effect of physical activity on affective states at work.

17 Further, an EMA methodology using mobile phones, which records time of response, was

18 used to examine momentary affective states during work time. Evidence pertaining to both

19 group-level and intra-individual differences in affective states is presented. In addition, walk

20 attendance records were completed by walk leaders as an objective assessment of behaviour.

21 Finally, Kanning, Ebner-Primer, and Schlicht (2013) have published a position statement on

22 methodological standards recommended for examining the within-subject associations

23 between physical activity and affect. These include 1) repeated measurement to capture the

24 dynamic associations between the variables, 2) the objective assessment of physical activity,

25 and 3) measuring affect in real time. These standards were adopted in the present paper. 


\section{Running head: AFFECTIVE CHANGES IN INACTIVE EMPLOYEES}

2 lunchtime walking intervention on momentary work-related affective outcomes, controlling

3 for a range of trait characteristics. To test these effects, both between-group and within-person

4 differences were examined. The research design allowed for group comparisons between

5 responses by the Immediate Treatment (IT) group and the Control phase of the Delayed

6 Treatment group (DT-C). Further, within-person differences were examined by comparing

7 responses of the IT and the Intervention phase of the DT (DT-I) by time of day (morning

8 versus afternoon) on active days (when participants had walked at lunchtime) and on active

9 versus inactive days. These analyses were conducted separately for both groups to explore the consistency in responses across the groups who had undergone the intervention at different times of the year. Specifically, the main hypothesis pertained to the between-group comparisons and predicted greater levels of enthusiasm and relaxation in IT than in the DT-C group, above and beyond any influence of trait variables and perceptions of workload on that day (H1). The additional analyses examined within-person changes. The within-person hypothesis relating to time of day predicted that participants (IT and DT-I) would report significantly greater levels of enthusiasm and relaxation in the afternoons than in the mornings on days when they had walked during lunchtime. In contrast, differences were not anticipated in fatigue or nervousness, due to inconsistent effects reported in previous literature (H2). For the Day analysis, it was predicted that levels of enthusiasm and relaxation, but not fatigue and nervousness, at work would be greater in the afternoon when the participants (IT and DT-I) had walked during lunchtime, compared to when they had not (H3).

\section{Materials and Methods}

\section{Participants}

Following University ethical approval for use of human subjects, participants were recruited through a University workplace well-being health fair, pay slip messages, flyers and 
Running head: AFFECTIVE CHANGES IN INACTIVE EMPLOYEES

1 posters, a monthly University staff informational magazine, and a specially designed website

2 (for further information on recruitment methods, including a CONSORT diagram, see

3 Authors, 2010; Authors, in press).

4

5

6 Initially, 249 participants were assessed for eligibility to partake in the intervention (see Authors, in press for the results relating to the feasibility of the intervention). Eligible participants had to be employed full-time in a non-academic (i.e., administrative) position, and they had to be physically inactive at baseline (i.e., engage in less than 150 minutes of moderate intensity physical activity per week as assessed by a brief screening questionnaire). A large proportion $(n=174)$ were excluded because they were sufficiently physically active (they already met physical activity recommendations for health). A total of 75 non-academic administrative University staff members ( $n=69$ females, $n=6$ males) were therefore recruited for the intervention. The participants worked in 32 (out of 43) different University departments or corporate services, and were representative in terms of ethnicity (Pearson $\chi^{2}$ $(1)=.01 ; p>.05)$, but not gender $\left(\right.$ Pearson $\left.\chi^{2}(1)=28.65 ; p<.01\right)$ as there was an overrepresentation of females. Thirty-five participants ( $n=32$ females, $n=3$ males) were randomised to an immediate treatment (IT) and 40 participants ( $n=37$ females, $n=3$ males) to a delayed treatment (DT) condition.

Eighteen participants who dropped out during the study period did not provide EMA ratings and were therefore not included in the data analyses (for more information about reasons for drop-out, please see Author(s), in press). There were no significant differences between the drop-outs and the adherers in age $(t(73)=1.52 ; p=.13)$, positive or negative affective traits measured at baseline (Pillai's Trace $=.00 ; F(2,71)=.02 ; p=.98$ ), selfreported physical activity (Pillai's Trace $=.07 ; F(4,70)=1.21 ; p>.05$; partial $\eta^{2}=.07$ ), or self-reported health $(t(73)=1.46 ; p=.15)$. One further participant, who adhered to the intervention, did not provide EMA data, so was also excluded from the analyses reported in 
Running head: AFFECTIVE CHANGES IN INACTIVE EMPLOYEES

1 this paper. Thus, for the purpose of this study, data from 56 ( $n=52$ women) participants were

2 used (IT: $n=26$; DT: $n=30$ ). This sample size is deemed to be adequate, as simulation

3 research has shown that approximately 50 level 2 units (i.e., individuals in our study) or more

4 are needed for accurate parameter estimates in multilevel modelling (Maas \& Hox, 2005), the

5 analyses used in the present study. The age range of the participants was 24 to 63 years $(M=$

$647.68, S D=10.31$ ) with $85.3 \%$ White British, $6.7 \%$ Asian, 4\% Black, 2.7\% Chinese, and

$7 \quad 1.3 \%$ 'Other' in ethnic representation.

\section{Design and Procedure}

9 Intervention. The intervention consisted of 10 weeks of group-led walks and a further 10 six weeks of independently organised walks. The participants were requested to take part in 11 three 30 minute group-led walks during lunchtime per week, and two walks during the 12 weekends which were independently organised. The following six weeks were independently 13 organised by the participants. The participants were encouraged to self-select their own 14 walking intensity/speed for each walk, and were provided with maps of the walks in case they 15 wanted to walk either faster or slower than the rest of the group.

16 For the present study, only analysed was data pertaining to the first 10 weeks of the 17 programme and only those derived from work days when the participants could sign up and 18 attend lunchtime walks at work. This was because attendance could only be objectively verified in the group phase through walk attendance records kept by the walk leaders. The DT 20 group started the intervention phase once the IT group had finished their intervention (in May 21 2010). The control phase for the DT group (DT-C; February 2010 start) was thus directly 22 comparable time-wise to the IT intervention which allowed for a true test of intervention 23 effects. Data for the DT group's intervention phase (DT-I) was also used, which meant that 24 the participants in the DT condition were asked to complete twice as many momentary reports 
Running head: AFFECTIVE CHANGES IN INACTIVE EMPLOYEES

1 compared to participants in the IT condition. During the DT-C, participants in the DT group

2 were requested not to change their usual pattern of behaviour.

3 Prior to the start of the intervention, walk leaders were recruited from the community

4 and trained in the provision of autonomy support (see Authors, 2010 for details). The

5 participants were requested to sign up for lunchtime walks using a Doodle poll. The

6 participants had a range of choices regarding routes in order to provide them with a degree of

7 autonomy and choose the walks they preferred. This was possible as different walks were

8 offered at the same time and a team of walk leaders was available. All participants were asked

9 to wear an unsealed Yamax Digi-Walker 351 pedometer at the beginning of the intervention

10 phase (participants in the DT condition did not acquire these until after the end of the control

11 phase) for monitoring and motivational purposes. They were also requested during the

12 intervention phase to log daily step counts in a booklet. Further, researchers sent twice weekly

13 motivational text messages to the participants during the intervention phase to encourage

14 participation.

15 Programming for EMA. Using a randomised time table generator, alarm times were

16 randomly allocated to two chosen days every week to ring once in the morning between 10.00

17 and 11.00 am and once again on the same day in the afternoon between 14.00 and $15.00 \mathrm{pm}$.

18 These timings were chosen because participants could take part in walks at different times

19 (12.30 or 1.15 p.m), and therefore it was not possible to prompts participants to respond right

20 before and after each walk. The timing of the prompts was randomised to prevent expectancy

21 effects. Participants were asked to complete the twice weekly scales for the duration of the 10

22 weeks of group-based walks (including DT-C phase). Nokia 2730 Classics mobile phones

23 were programmed using JAVA Micro Edition (Java ME, Oracle). The programmer uploaded

2426 questions for the morning alarms asking whether the participants were at work, and

25 questions related to job affect. The afternoon questions were the same as the morning with the 


\section{Running head: AFFECTIVE CHANGES IN INACTIVE EMPLOYEES}

1 addition of a single question related to perceived work load during that day. Additionally, the

2 phones were programmed to provide a reminder signal 30 minutes later if there was no

3 response to the initial alarm. To avoid multiple responses to the alarm, the phones were

4 programmed to accept data only once within that 30 minute window. The phones were

5 programmed to record the time of completion and questions were presented in a random order

6 to avoid ordering effects.

\section{$7 \quad$ Measures and Instrumentation}

Walk attendance. The walk leaders held attendance records for each walk. The participants who turned up for the walks were asked to provide their ID number which was noted by the walk leader. These data were matched by date and time to affect responses from the phones.

Job Affect. The Job Affect Scale (JAS) was developed by Brief et al. (1988) and consists of 20 items describing positive and negative affect. In a subsequent study employing confirmatory factor analytic techniques, Burke et al. (1989) showed that the 20 mood states were most appropriately identified as four unipolar factors: enthusiasm (six items), relaxation (four items), nervousness (six items), and fatigue (four items). The scale asks participants the extent to which they have experienced each of the 20 mood descriptors at work in the past week. The response scale ranges from 1 ('very slightly or not at all') to 5 ('very much'). In the present study, the traditional version of the scale was used at baseline (to assess trait jobrelated affect) and was administered via a traditional paper and pencil questionnaire. An adapted state measure of the scale to assess momentary affect was also used. Here, participants were asked to report how they felt 'right now'. The momentary measure was programmed into the mobile phones. Support for the internal consistency of the original JAS has been reported in previous research (Thøgersen-Ntoumani et al., 2005).

\section{Control variables}




\section{Running head: AFFECTIVE CHANGES IN INACTIVE EMPLOYEES}

1

2 posed in the afternoon asking the participants to judge how heavy their workload was on that

3 day. The response scale ranged from 1 ('very heavy') to 5 ('very light'), and the scores were

4 reversed before being entered into the analysis.

Positive and negative affectivity. The trait version of the Positive and Negative

Affect Schedule (PANAS) (Watson et al., 1988) was used to assess trait positive and negative affectivity which was assessed at baseline only via a paper and pencil questionnaire. The scale consists of 20 items; 10 measuring positive affect and 10 items assessing negative affect.

Participants were asked how often, in general in their life as a whole, they experienced each of 10 positive (e.g., enthusiastic, determined, proud, attentive) and 10 negative (e.g., distressed, hostile, nervous, jittery) states. This measure is scored on a scale ranging from 1 ('not at all') to 5 ('very much'). Evidence regarding the reliability and validity of the scale has been reported elsewhere (e.g., Crawford \& Henry, 2004).

Motivation to work. The Work Extrinsic and Intrinsic Motivation Scale (WEIMS) (Tremblay et al., 2010) is an 18-item questionnaire used to assess extrinsic and intrinsic work motivation. Participants are asked to respond to what extent each of a number of statements corresponds to the reasons why they are currently involved in their work, with a response scale ranging from 1 ('does not correspond at all') to 7 ('corresponds exactly'). The questionnaire measures amotivation (AM; e.g., 'I don't know, too much is expected of us'), external regulation (EX; e.g., 'for the income it provides me'), introjected regulation (IJ; e.g., 'because I want to succeed in this job, if not I would be very ashamed of myself'), identified regulation (ID; e.g., 'because it is the type of work I have chosen to attain certain important objectives'), integrated regulation (INT; e.g., 'because it has become a fundamental part of who I am'), and intrinsic motivation (IM; e.g., 'for the satisfaction I experience when I am successful at doing difficult tasks'). For the purpose of the present study, using Tremblay et 


\section{Running head: AFFECTIVE CHANGES IN INACTIVE EMPLOYEES}

1 al.'s (2010) instructions, we converted the scores of each subscale into a work self-

2 determination index. A resultant positive overall score represented self-determined work

3 motivation and a negative score was indicative of a non-self-determined profile. Tremblay et

4 al. (2010) reported a Cronbach's alpha coefficient of $\alpha=.84$ as well as evidence to support

5 the scale's construct validity.

Data analyses. Following the calculation of descriptive statistics and bivariate

7 correlations, three sets of main analyses ( 1 between-group and 2 within-person) were

8 conducted. The between-group analyses compared responses in affect between IT and DT-C

9 on afternoons when the IT group participants had walked at lunchtime. The first set of within-

10 group analyses examined changes in affective states from morning to afternoons on days

11 when the groups (IT and DT-I) had walked at lunchtime. The second set examined differences

12 in affective states on afternoons when the participants had walked at lunchtime compared to

13 days when they had not. For the within-person analyses, the groups (IT and DT-I) were

14 analysed separately to examine whether the intervention worked similarly at different times of

15 the year as the IT group had their intervention in February to April, while the DT group

16 experienced their intervention between May and July.

17 Multilevel modelling (also called mixed linear modeling), using MLWin (version

18 2.25) (Rasbash et al., 2012), was used to analyse H1-H3, as there were repeated observations

19 (level 1) nested within individuals (level 2). In these analyses predicted changes were in

20 enthusiasm, relaxation, nervousness and fatigue as a function of group status (binary coded as

$21 \mathrm{IT}=1$, DT-I $=0)$, morning vs. afternoon $($ morning $=0$, afternoon $=1)$, and walking day vs.

22 non-walking day (walking day $=1$, non-walking day $=0$ ). In all models the researchers

23 controlled for the trait equivalent of the outcome affect measure, negative and positive

24 affectivity, and work motivation (and daily workload for $\mathrm{H} 1$ and $\mathrm{H} 3$ ). This was because

25 previous research has shown that these variables relate to well-being responses (DeNeve \& 
Running head: AFFECTIVE CHANGES IN INACTIVE EMPLOYEES

1 Cooper, 1998; Heller et al., 1998; Steel et al., 2008). As these variables were measured once

2 and, therefore, entered as Level 2 variables in the multilevel equations, we grand mean

3 centered these variables (Enders \& Tofighi, 2007). In addition, perceived daily workload was

4 considered as a potential confounder, so this variable was also taken into account in relevant

5 analyses. This variable was group mean centered to control for the influence of changes in

6 workload relative to each participants' unique mean (Enders \& Tofighi, 2007). All variables

7 were treated as fixed effects as we were concerned with average effects across the sample and

8 keeping the models as parsimonious as possible (i.e., the minimum number of parameters to

9 explain variance in the dependent variables).

\section{Results}

\section{Preliminary Analyses}

$N=1,377$ useable phone entries were gathered in total from 56 employees providing a mean entry response of 24.59 per employee. This represented an overall response rate to the

14 mobile phone alarms of $39.70 \%$. Of the entries, $n=807(58.60 \%)$ were recorded on days

15 when participants did not walk, while $n=570$ (41.40\%) were recorded on days when the

16 participants walked at lunchtime. On average, participants completed 19.88 group-led walks,

17 which represents $66.27 \%$ of the total number of walks.

18 Table 1 presents the descriptive statistics and the bivariate correlations between all the

19 variables in the study. The results provided support for the internal reliability of all the scales.

20 The correlation analyses revealed expected patterns of relationships. For example, the four

21 affective states measured via the mobile phones were most highly correlated with their

22 respective trait equivalents, yet they were distinct. Further, the associations between the

23 affective states were either non-significant or moderate in size which supports the

24 independence of the four affective states. The associations between components of the JAS 


\section{Running head: AFFECTIVE CHANGES IN INACTIVE EMPLOYEES}

1 and positive and negative affectivity from the PANAS were also all small-moderate in size

2 and/or non-significant. This supports the decision to retain all in the main analyses.

3

4

(Table 1 about here)

As a randomisation check, the IT and DT groups were compared on all demographic and trait characteristics measured at baseline. Chi-square tests revealed no differences in gender $\left(\right.$ Pearson $\left.\chi^{2}(1,51)=.18 ; p>.05\right)$ or ethnicity $\left(\right.$ Pearson $\left.\chi^{2}(3)=1.05 ; p>.05\right)$ between the conditions. Further, an independent sample t-test showed no differences in age $(t(49)=$ $.03 ; p>.05)$. A one-way MANOVA revealed no significant group differences between the groups in baseline work affect (Pillai’s Trace $=.068 ; F(4,69)=1.26 ; p>.05$ ).

\section{Main Analyses}

To test the main hypothesis (H1), afternoon responses on days when participants in the IT condition had walked during lunchtime were compared with afternoon responses of the DT participants in the afternoon of the same day (DT-C phase). The results (see Table 2) showed that participants in the IT condition reported greater levels of enthusiasm and relaxation compared to the other group above and beyond any influence of the control variables. However, there were no differences between the groups in nervousness or fatigue. (Table 2 about here)

Next, in testing $\mathrm{H} 2$, the researchers examined intra-individual variation in changes in responses from morning to afternoons on walking days. These analyses were conducted separately for the two groups. The results revealed some differences between the groups (see Table 3). While nervousness reduced from the morning to the afternoon in both groups, both relaxation and fatigue increased following walks in the IT group only.

(Table 3 about here)

Finally, addressing H3, the results showed that on days in which participants walked during lunchtimes, they experienced significantly greater levels of enthusiasm and relaxation 


\section{Running head: AFFECTIVE CHANGES IN INACTIVE EMPLOYEES}

1 at work during the afternoon compared to afternoons when they had not walked at lunchtime

2 (see Table 4). This was evident in both the IT and the DT group. In addition, delayed

3 treatment participants (DT-I phase) experienced lower levels of nervousness at work on

4 afternoons of walking days compared to afternoons on non-walking days. There were no

5 differences in the remaining outcome variables.

6

7

(Table 4 about here)

\section{Discussion}

In this study we aimed to examine in a mainly female sample the effects of lunchtime walks on (changes in) job-related affective states during the working day in the context of a randomised trial using an EMA methodology. The hypotheses were largely supported.

Specifically, beyond any influence of positive and negative affectivity, equivalent traits, work motivation and perceived workload, participants in the IT group reported greater levels of enthusiasm and relaxation at work in the afternoon compared to participants in the DT condition (DT-C phase) observed in the afternoon of the same day. Walking therefore seems to have both energising and relaxing properties in the workplace, which supports the main hypothesis of the study. The within-person analysis comparing afternoon responses on walking versus non-walking days confirmed the results of the between-group analysis as afternoons following walks were associated with greater levels of enthusiasm and relaxation. Given recent findings from the meta-analysis by Ford et al. (2011) that affective experiences at work are linked to workplace performance, these results may have broader implications for the success of companies.

However, the additional within-person analysis revealed a different pattern of results. Specifically, nervousness decreased from the mornings to the afternoons on walking days in both groups. Thus, a 30 minute group walk appears to have stress reducing properties in physically inactive employees. A similar pattern was found when we compared the afternoons 
Running head: AFFECTIVE CHANGES IN INACTIVE EMPLOYEES

1 on walking days with afternoons of non-walking days, but only for the DT group. Workplace

2 physical activity interventions can reduce general stress levels (moderate effect of $d=.33$ ) as

3 reported in a meta-analysis by Conn et al. (2009). This is despite studies which have revealed

4 no association between physical activity and negative affect at the daily level (Wichers et al.,

5 2011; Giacobbi et al., 2005; Ready et al., 2009). Thus, there appears to still be some

6 inconsistency in research examining the effects of physical activity on stress or nervousness.

7 The present study builds on the research by showing nervousness can be reduced within the

8 same day as a result of a lunchtime walk.

9 The findings related to fatigue were largely supportive of the hypotheses. Specifically,

10 there were no group differences in fatigue in the afternoons when the IT group had walked

11 during lunchtime. The within-person analyses also showed no differences in fatigue between

12 afternoons following walking activity compared to afternoons on non-walking days. These

13 results are in accordance with the recent meta-analysis conducted by Loy et al (2013) showing

14 inconsistent effects of acute bouts of low-to-moderate intensity exercise on fatigue. Although

15 a meta-analysis by Puetz et al. (2006) documented moderate sized decreases in fatigue

16 following chronic participation, most of the participants included in the analysis were patient

17 groups. It is possible that the effect of physical activity on fatigue differ between clinical and

18 non-clinical groups, with stronger effects for clinical populations.

19 However, when levels of fatigue were compared in the mornings versus afternoons on 20 walking days (H2), IT group participants experienced increases, while there were no changes 21 in the DT group. These differences between the groups were unexpected, but the finding may 22 be explained by seasonal variation. A recent EMA study by Kööts et al. (2011) has revealed 23 that momentary ratings of high levels of fatigue were more likely in cold and dark conditions.

24 This explanation may be relevant here as the IT group began their intervention in the cold

25 winter (February) months when the average temperature was $2.4{ }^{\circ} \mathrm{C}$ and the DT group started 
Running head: AFFECTIVE CHANGES IN INACTIVE EMPLOYEES

1 their intervention phase in lighter spring conditions (May) when the average temperature was

$210.7^{\circ} \mathrm{C}$. In future, it may also be useful to examine effects on fatigue at various stages of an

3 intervention (e.g., adoption versus adherence phases).

4

\section{Strength and Limitations}

In the present study, statistical approaches including EMA and multilevel techniques

were used to control for error and confounding effects of extraneous variables and comparison

was made with a randomised control group or participants acted as their own controls for

some analyses. The study therefore provides a rigorous examination of the fluctuations and differences in affective states arising as a consequence of physical activity participation. In contrast, previous studies in this area have used observational designs (Kanning \& Schlicht, 2010; Wichers et al., 2011; Giacobbi et al., 2005; Ready et al., 2009). Another strength was that attendance in the walking sessions was objectively measured via records kept by the walk leaders unlike previous studies where researchers have relied on self-reported measures (Kanning \& Schlicht, 2010; Wichers et al., Hausenblas et al., 2008). Finally, this research was conducted with physically inactive employees, where previous studies have observed already active individuals. Clearly, the public health implications of identifying effective physical activity interventions for those who are at greater risk of disease, obesity, mental health problems etc. (as are the physically inactive) are important. Nonetheless, the intervention may be suitable for all employees regardless of habitual levels of physical activity and it would be important in future research to examine which groups may benefit the most.

Although the findings cannot be generalized to males given the low number of males in the intervention, the sample was representative in terms of ethnicity, and participants represented a range of job roles across the University setting. These factors strengthen the external validity of our results. 


\section{Running head: AFFECTIVE CHANGES IN INACTIVE EMPLOYEES}

However, there are also limitations associated with this study. First, the findings

cannot be generalized to male employees. As yet it is unknown whether the affective responses of men differ from those of women as a result of walking interventions as few interventions have been conducted with males. This would be a worthy avenue of future research. The gender imbalance in the intervention is consistent with other reviews showing that females are more likely than males to sign up for employee wellness programmes (Robroek, van Lenthe, vam Empelen, \& Burdorf, 2009) or take part in group-based walking interventions (Kassavou, Turner, \& French, 2013).

Further, the analyses did not control for diurnal variations in moods. Indeed, Gauvin and Spence (1996) have shown that positive mood tends to be highest around midday while it is lower in the morning, the afternoon and the evening. It is possible that such fluctuations could partly explain the differences in some affect ratings between morning and afternoons on walking days in the present study. However, the fact that two of our main analyses (one between-groups and another within-person) compared affective responses in the afternoons as a function of group and walking versus non-walking day refutes the argument that diurnal variations in affect can explain our results.

Another limitation relates to the relatively low response rates to the signals emitted by the mobile phones. The decision was made to retain all responses. This was because one of the strengths of multilevel modeling analysis is its ability to deal with incomplete data (Singer $\&$ Willet, 2003). The fact that the EMA approach was used over a prolonged period of time (twice daily on two days per week for 10 weeks in the IT and for 20 weeks in the DT condition) may have negatively affected the response rates. These intervals may need to be reviewed in future research.

In addition, it is important to note that the JAS used to assess job affect was designed to measure trait affect at work but was adapted for use in the present study to assess states. 
Running head: AFFECTIVE CHANGES IN INACTIVE EMPLOYEES

1 Although it is well established that affective experiences exist at both trait and state levels

2 (see e.g., the Positive and Negative Affect Scale developed by Watson, Clark and Tellegen,

3 1988), the effects for the between-group analyses were stronger than for the within-person

4 analyses, which suggests that fluctuations in work affect states may not differ much from their

5 average levels. There were also differences in the results depending on whether between-

6 group or within-person analyses were conducted. It is important in future research to ascertain

7 that the modified JAS is the most appropriate measure for assessing momentary work-related

8 states.

9 Finally, it is important to emphasize that, as the walks were completed in groups, it is

10 not possible to separate the effects of social interaction versus the walking itself on changes in

11 affective states. Some previous research has examined the effects of moderate intensity

12 physical activity on affective states when done alone versus with one other person (e.g., a

13 friend; Johansson, Hartig, \& Staats, 2011; Plante, Coscarelli, \& Ford, 2001). These studies

14 have shown that a bout of physical activity on one's own results in improvements in some

15 affective states (e.g., positive affect, energy, revitalisation) but also that this appears to be

16 dependent on where the activity is completed (e.g., in a park versus on streets). Examining the

17 roles of both the social and physical environment to affect regulation using a similar walking

18 intervention to the one reported in this study could be a useful avenue for future research.

\section{Perspective}

21 Improving the health and well-being of employees is a key concern to the

22 Government, public health bodies and global health organisations. The increase in sedentary

23 jobs requires innovative solutions to help get employees more physically active at work. The

24 lunchtime walking programme tested as part of this study targeted to a traditionally hard to

25 reach group (i.e., physically inactive employees) indicated that it was effective in regulating 
Running head: AFFECTIVE CHANGES IN INACTIVE EMPLOYEES

1 (most) affective states at work. Enthusiasm, relaxation, and nervousness at work improved as

2 a result of the walking intervention, but patterns of results differed depending on whether

3 between-group or within-person analyses were conducted. Thus, the effect of physical activity

4 and affect is complex suggesting that individual factors play an important role. Given the

5 adaptive role of affective states of work and the potential public health and cost saving

6 implications of improving well-being at work, more research should be conducted to examine

7 the longer-term effects of this intervention.

\section{Acknowledgements}

9 This work was supported by The BUPA Foundation under Grant TBF08004. 


\section{Running head: AFFECTIVE CHANGES IN INACTIVE EMPLOYEES}

\section{References}

2 Author(s) (in press).

3 Author(s) (2010).

4 Brief AP, Burke MJ, George JM, Robinson BS, Webster J: Should negative affectivity remain

5 an unmeasured variable in the study of job stress? J Appl Psychol 1988, 73:193-198.

6 Brown HE, Gilson ND, Burton NW, Brown WJ: Does physical activity impact on

7 presenteeism and other indicators of workplace well-being? Sports Med 2011, 41:249-262.

8 Burke MJ, George JM, Brief AP, Roberson L, Webster J: Measuring affect at work:

9 Confirmatory analyses of competing mood structures with conceptual linkage to cortical

10 regulatory systems. J Pers Soc Psychol 1989, 57:1091-1102.

11 Chan CB, Ryan DAJ, Tudor-Locke C: Health benefits of a pedometer-based physical activity

12 intervention in sedentary workers. Prev Med 2004, 39:1215-1222.

13 Conn VS, Hafdahl AR, Cooper PS, Brown LM, Lusk SL: Meta-analysis of workplace

14 physical activity interventions. Am J Prev Med 2009, 37:330-339.

15 Coulson JC, McKenna J, Field M: Exercising at work and self-reported work performance. Int 16 J Workpl Health Manage 2008, 1:176-197.

17 Crawford JR, Henry JD: The Positive and Negative Affect Schedule (PANAS): Construct 18 validity, measurement properties and normative data in a large non-clinical sample. Br J Clin 19 Psychol 2004, 43:245-265.

20 DeNeve KM, Cooper H: The happy personality: A meta-analysis of 137 personality traits and 21 subjective well-being. Psychol Bull 1998, 124:197-229.

22 Dugdill L, Brettle A, Hulme C, McCluskey S, Long AF: Workplace physical activity 23 interventions: A systematic review. Int J Workpl Health Manage 2008, 1:20-40.

24 Enders CK, Tofighi D: Centering predictor variables in cross-sectional multilevel models: A 25 new look at an old issue. Psychol Methods 2007, 12:121-138. 
Running head: AFFECTIVE CHANGES IN INACTIVE EMPLOYEES

1 Ford MT, Cerasoli CP, Higgins JA, Decesare AL: Relationships between psychological,

2 physical, and behavioral health and work performance: A review and meta-analysis. Work

3 Stress 2011, 25:185-204.

4 Gauvin L, Rejeski WJ, Norris, JL: A naturalistic study of the impact of acute physical activity

5 on feeling states and affect in women. Health Psychol 1996, 15:391-397.

6 Gauvin L, Spence JC: Physical activity and psychological well-being: Knowledge base,

7 current issues and caveats. Nutr Rev 1996, 54:S53-S65.

8 Giacobbi PR, Hausenblas HA, Frye N: A naturalistic assessment of the relationship between

9 personality, daily life events, leisure-time exercise, and mood. Psychol Sport Exerc 2005,

$10 \quad 6: 67-81$.

11 Gilson N, McKenna J, Cooke C, Brown W: Walking towards health in a university

12 community: A feasibility study. Prev Med 2007, 44:167-169.

13 Hausenblas HA, Gauvin L, Symons Downs D, Duley AR: Effects of abstinence from habitual

14 involvement in regular exercise on feeling states: An ecological momentary assessment study.

15 Br J Health Psychol 2008, 13:237-255.

16 Hecht TD, Boies K: Structure and correlates of spillover from nonwork to work: An

17 examination of nonwork activities, well-being, and work outcomes. J Occup Health Psychol

$182009,14: 414-426$.

19 Hektner JM, Schmidt JA, Csikszentmihalyi M: Experience Sampling Method: Measuring the

20 Quality of Everyday Life. Thousand Oaks, Sage Publications 2007.

21 Heller D, Judge TA, Watson D: The confounding role of personality and trait affectivity in the

22 relationship between job and life satisfaction. J Organ Behav 2002, 23:815-835.

23 Johansson M, Hartig T, Staats H: Psychological benefits of walking: Moderation by company

24 and outdoor environment. Appl Psychol: Health Well-Being 2011, 3:261-280. 
Running head: AFFECTIVE CHANGES IN INACTIVE EMPLOYEES

1 Kanning MK, Ebner-Priemer UW, Schlicht WM: How to investigate within-subject

2 associations between physical activity and momentary affective states in everyday life: A

3 position statement based on a literature overview. Front Psychol 2013, 4:187.

4 Kanning M, Schlicht W: Be active and become happy: An ecological momentary assessment

5 of physical activity and mood. J Sport Exerc Psychol 2010, 32:253-261.

6 Kassavou A, Turner A, French DP: Do interventions to promote walking in groups increase

7 physical activity? A meta-analysis. Int J Behav Nutr Phys Activ 2013, 10:18.

8 Kööts L, Realo A, Allik J: The influence of the weather on affective experience: An

9 experience sampling study. $J$ Ind Diff 2011, 32:74-84.

10 Lee IM, Shiroma EJ, Lobelo F, Puska P, Blair SN, Katzmarzyk PT: Effect of physical

11 inactivity on major non-communicable diseases worldwide: An analysis of burden of disease

12 and life expectancy. Lancet 2012, 380:219-229.

13 Maas CJM, Hox JJ: Sufficient sample sizes for multilevel modeling. Methodology 2005, 1:86-

1492.

15 Penedo FJ, Dahn JR: Exercise and well-being: a review of mental and physical health benefits 16 associated with physical activity. Curr Opin Psychiatr 2005. 18:189-193.

17 Plante TG, Coscarelli L, Ford M: Does exercising with another enhance the stress-reducing 18 benefits of exercise? Int J Stress Managem 2001, 8:201-213.

19 Puetz TW, O’Connor PJ, Dishman RK: Effects of chronic exercise on feelings of energy and 20 fatigue: A quantitative synthesis. Psychol Bull 2006, 132:866-876.

21 Rasbash J, Browne WJ, Healy M, Cameron B, Charlton CMJ: MLwiN Version 2.25 2012.

22 Ready RE, Marquez DX, Akerstedt A: Emotion in younger and older adults: Retrospective 23 and prospective associations with sleep and physical activity. Exp Aging Res 2009, 35:34824368. 


\section{Running head: AFFECTIVE CHANGES IN INACTIVE EMPLOYEES}

1 Reed J, Buck S: The effect of regular aerobic exercise on positive-activated affect: A meta-

2 analysis. Psychol Sport Exerc 2009, 10:581-594.

3 Reed J, Ones DS: The effect of acute aerobic exercise on positive activated affect: A meta-

4 analysis. Psychol Sport Exerc 2006, 7:477-514.

5 Robroek SJW, van Lenthe FJ, van Empelen P, Burdorf A: Determinants of participation in

6 worksite health promotion programmes: A systematic review. Int J Behav Nutr Phys Activ

$7 \quad 2009,6: 26$

8 Salanova M, Del Libano M, Llorens S, Schaufeli WB: Engaged, workaholic, burned-out of

9 just 9-to-5? Toward a typology of employee well-being. Stress Health 2014, 30:71-81.

10 Samkoff JS, Jacques CH: A review of studies concerning the effects of sleep deprivation and

11 fatigue on residents' performance. Acad Med 1991, 66:687-693.

12 Singer JD, Willet JB: Applied Longitudinal Data Analysis: Modeling Change and Event

13 Occurrence. Oxford, University Press 2003.

14 Steel P, Schmidt J, Shultz J: Refining the relationship between personality and subjective 15 well-being. Psychol Bull 2008, 134:138-161.

16 Thayer RE, Newman JR, McClain TM: Self-regulation of mood: strategies for changing a bad

17 mood, raising energy, and reducing tension. J Pers Soc Psychol 1994, 67:910-925.

18 Thøgersen-Ntoumani C, Fox KR, Ntoumanis N: Relationships between exercise and three

19 components of mental well-being in corporate employees. Psychol Sport Exerc 2005, 6:60920627.

21 Thomas DL, Diener E: Memory accuracy in the recall of emotions. J Pers Soc Psychol 1990, $22 \quad 59: 291-297$.

23 Tremblay MA, Blanchard CM, Taylor S, Pelletier LG, Villeneuve M: Work Extrinsic and 24 Intrinsic Motivation Scale: Its value for organizational psychology research. Can J Behav Sci $252010,41: 213-226$. 
1 Watson D, Clark LA, Tellegen A: Development and validation of brief measures of positive

2 and negative affect: The PANAS scales. J Pers Soc Psychol 1988, 54:1063-1070.

3 Wichers M, Peeters F, Jacobs N, Derom C, Thiery E, Delespaul P, van Os J: A time-lagged

4 momentary assessment study on daily life physical activity and affect. Health Psychol 2011, $5 \quad 31: 135-144$. 


\section{Running head: AFFECTIVE CHANGES IN INACTIVE EMPLOYEES}

Table 1. Descriptive Statistics and Correlations Among the Study Variables

\begin{tabular}{|c|c|c|c|c|c|c|c|c|c|c|c|c|c|c|c|c|}
\hline & $\alpha$ & $\mathrm{ICC}$ & $M$ & $S D$ & 1 & 2 & 3 & 4 & 5 & 6 & 7 & 8 & 9 & 10 & 11 & 12 \\
\hline 1. Enthusiasm (state) & .95 & .59 & 2.28 & .64 & & .61 & -.06 & -.42 & .69 & .38 & -.31 & -.38 & -.24 & .50 & .25 & -.05 \\
\hline 2. Relaxation (state) & .91 & .46 & 2.42 & .57 & & & -.11 & -.06 & .43 & .60 & -.31 & -.21 & -.22 & .22 & .11 & -.35 \\
\hline 3. Nervousness (state) & .90 & .32 & 1.28 & .31 & & & & .22 & -.11 & .01 & .37 & .28 & .35 & -.22 & .03 & .23 \\
\hline 4. Fatigue (state) & .92 & .38 & 1.56 & .45 & & & & & -.52 & -.22 & .25 & .62 & .25 & -.39 & -.04 & -.01 \\
\hline 5. Enthusiasm (trait) & .81 & & 2.58 & .71 & & & & & & .46 & -.48 & -.52 & -.36 & .61 & .31 & .05 \\
\hline 6. Relaxation (trait) & .82 & & 2.68 & .79 & & & & & & & -.42 & -.02 & -.08 & .19 & .08 & -.15 \\
\hline 7. Nervousness (trait) & .86 & & 1.75 & .78 & & & & & & & & .37 & .62 & -.37 & .06 & .09 \\
\hline 8. Fatigue (trait) & .88 & & 2.20 & 1.04 & & & & & & & & & .37 & -.32 & -.05 & -.03 \\
\hline 9. NA (PANAS) & .90 & & 2.16 & .70 & & & & & & & & & & -.43 & -.03 & -.07 \\
\hline 10. PA (PANAS) & .93 & & 3.19 & .75 & & & & & & & & & & & .38 & .26 \\
\hline 11. Work motivation & .78 & & 4.03 & .77 & & & & & & & & & & & & .18 \\
\hline 12. Workload & - & & 3.42 & .60 & & & & & & & & & & & & \\
\hline
\end{tabular}

Note. $r$ 's $\geq .28$ are significant at the $\alpha=.05$ level. 
Running head: AFFECTIVE CHANGES IN INACTIVE EMPLOYEES

Table 2. Between-Group Comparisons in Affective Responses on Afternoons following Walking at Lunchtime

\begin{tabular}{|c|c|c|c|c|}
\hline IV & Enthusiasm at work & Relaxation at work & Nervousness at work & Fatigue at work \\
\hline & $\beta(S E)$ & $\beta(S E)$ & $\overline{\beta(S E)}$ & $\beta(S E): Z$ \\
\hline Group $(0=\mathrm{DT} ; 1=\mathrm{IT})$ & $.45(.12)^{* *}(20.33 \%)$ & $.65(.12)^{* *}(53.64 \%)$ & $.03(.07)(0 \%)$ & $-.05(.12)(0 \%)$ \\
\hline Trait equivalent & $.46(.10)^{* *}$ & $.28(.08)^{* *}$ & $.20(.06) 3^{* *}$ & $.34(.07)^{* *}$ \\
\hline Negative affectivity & $.04(.09)$ & $-.07(.08)$ & $.02(.06)$ & $-.11(.09)$ \\
\hline Positive affectivity & $.18(.12)$ & $.10(.09)$ & $-.05(.05)$ & $-.20(.10)^{*}$ \\
\hline Work motivation & $.01(.01)$ & $.001(.01)$ & $.01(.01)$ & $.01(.01)$ \\
\hline \multirow[t]{4}{*}{ Workload } & $-.09(.03)^{* *}$ & $.14(.04)^{* *}$ & $-.10(.03)^{* *}$ & $-.01(.04)$ \\
\hline & 639.05 & 784.70 & 419.24 & 789.06 \\
\hline & \multicolumn{4}{|c|}{$\Delta-2 * \log L$ compared to unconditional model } \\
\hline & $58.56 * *$ & $63.51 * *$ & $34.45 * *$ & $31.65 * *$ \\
\hline
\end{tabular}

Notes. IT $=$ Immediate Treatment condition $(n=26) ; \mathrm{DT}=$ Delayed Treatment $(n=30)$ condition. ${ }^{*}=p<.05 ; * *=p<.01$.

For Group, walking afternoons in the IT condition are compared to afternoons in the DT (DT-C phase) condition. 


\section{Running head: AFFECTIVE CHANGES IN INACTIVE EMPLOYEES}

The percentages indicate the reduction in the between-person variability of the intercept due to the inclusion of the group variable (pseudo- $R^{2}$ for level 2). The values for pseudo- $R^{2}$ for level 1 are zero because the group variable is a purely level 2 explanatory variable. In all models, the variance of level 1 and level 2 residual errors were significantly different from zero. 
Running head: AFFECTIVE CHANGES IN INACTIVE EMPLOYEES

Table 3. Within-Person Comparisons of Morning and Afternoon Affective Responses on Walking Days in both Groups

\begin{tabular}{|c|c|c|c|c|c|c|c|c|}
\hline \multirow[t]{2}{*}{ IV } & \multicolumn{2}{|c|}{ Enthusiasm at work } & \multicolumn{2}{|l|}{ Relaxation at work } & \multicolumn{2}{|c|}{ Nervousness at work } & \multicolumn{2}{|l|}{ Fatigue at work } \\
\hline & IT & DT & IT & DT & IT & DT & IT & DT \\
\hline & $\beta(S E)$ & $\beta(S E)$ & $\beta(S E)$ & $\beta(S E)$ & $\beta(S E)$ & $\beta(S E)$ & $\beta(S E)$ & $\beta(S E)$ \\
\hline Time of Day & $-.01(.05)(0 \%)$ & $-.03(.06)(0 \%)$ & $.17(.06)^{* *}(2.9 \%)$ & $.06(.06)(0 \%)$ & $-11(.04)^{* *}(2.1 \%)$ & $-.12(.04)^{* *}(2.7 \%)$ & $.11(.05) *(1.4 \%)$ & $.03(.06)(0 \%)$ \\
\hline \multicolumn{9}{|l|}{$(0=\mathrm{am} ;$} \\
\hline \multicolumn{9}{|l|}{$1=\mathrm{pm})$} \\
\hline Trait equivalent & $.61(.17)^{* *}$ & $.11(.11)$ & $.38(.10)^{* *}$ & $-.004(.11)$ & $.42(.10)^{* *}$ & $-.19(.08)^{*}$ & $.16(.07)^{*}$ & $.04(.08)$ \\
\hline Negative & $.08(.24)$ & $.07(.09)$ & $-.38(.18)^{*}$ & $-.08(.11)$ & $.14(.14)$ & $.10(.08)$ & $.16(.16)$ & $-.02(.09)$ \\
\hline \multicolumn{9}{|l|}{ affectivity } \\
\hline Positive & $.21(.17)$ & $.34(.14)^{*}$ & $-.01(.12)$ & $.28(.13)^{*}$ & $-.06(.09)$ & $-.04(.08)$ & $.08(.11)$ & $-.40(.11)^{* *}$ \\
\hline \multicolumn{9}{|l|}{ affectivity } \\
\hline Work & $.02(.02)$ & $.001(.01)$ & $.02(.01)$ & $-.03(.01)^{*}$ & $.004(.01)$ & $-.01(.01)$ & $-.01(.01)$ & $.01(.01)$ \\
\hline \multicolumn{9}{|l|}{ motivation } \\
\hline & & & & & ${ }^{*} \log \mathrm{L}$ & & & \\
\hline & 488.32 & 408.81 & 591.61 & 445.82 & 337.26 & 215.02 & 490.22 & 467.34 \\
\hline
\end{tabular}


Running head: AFFECTIVE CHANGES IN INACTIVE EMPLOYEES

$\Delta-2 * \log L$ compared to unconditional model

\begin{tabular}{|l|l|l|l|l|l|l|l}
\hline $19.70^{* *}$ & $21.48^{* *}$ & $28.17^{* *}$ & 8.27 & $27.76^{* *}$ & $13.89^{*}$ & $13.36^{*}$ & $15.86^{* *}$ \\
\hline
\end{tabular}

Notes. IT $=$ Immediate Treatment condition $(n=26) ; \mathrm{DT}=$ Delayed Treatment condition $(n=30) . *=p<.05 ; * *=p<.01$.

The percentages indicate the reduction in the within-person variability of the intercept due to the inclusion of the time of the day variable (pseudo- $R^{2}$ for level 1). The values for pseudo- $R^{2}$ for level 2 are zero or negative because the time of day variable is a purely level 1 explanatory variable. In all models, the variance of level 1 and level 2 residual errors were significantly different from zero. 
Running head: AFFECTIVE CHANGES IN INACTIVE EMPLOYEES

Table 4. Within-Person Comparisons in Afternoon Affective Responses on Walking Days versus Non-Walking Days in both Groups

\begin{tabular}{|c|c|c|c|c|c|c|c|c|}
\hline \multirow[t]{3}{*}{ IV } & \multicolumn{2}{|c|}{ Enthusiasm at work } & \multicolumn{2}{|c|}{ Relaxation at work } & \multicolumn{2}{|c|}{ Nervousness at work } & \multicolumn{2}{|c|}{ Fatigue at work } \\
\hline & IT & DT & IT & DT & IT & DT & IT & DT \\
\hline & $\beta(S E)$ & $\beta(S E)$ & $\beta(S E)$ & $\beta(S E)$ & $\beta(S E)$ & $\beta(S E)$ & $\beta(S E)$ & $\beta(S E): Z$ \\
\hline Day $(0=$ non- & $.18(.06)^{* *}$ & $.18(.07)^{* *}$ & $16(.07)^{*}$ & $.35(.08)^{* *}$ & $-.03(.05)$ & $-.15(.06)^{*}$ & $-.12(.07)$ & $-.04(.09)$ \\
\hline walking day; & $(8.7 \% ; 2.4 \%)$ & $(16.6 \% ; 2.2 \%)$ & $(5.5 \% ; 1.1 \%)$ & $(22.4 \% ; 9.2 \%)$ & $(3.4 \% ; 0 \%)$ & $(0 \% ; 2.8 \%)$ & $(8.5 \% ; 0 \%)$ & $(0 \% ; 0 \%)$ \\
\hline \multicolumn{9}{|l|}{$1=$ walking } \\
\hline day) & & & & & & & & \\
\hline Trait & $.69(.17)^{* *}$ & $.39(.13)^{* *}$ & $.35(.12)^{* *}$ & $.10(.11)$ & $.32(.08)^{* *}$ & $-.16(.09)$ & $.22(.08)^{* *}$ & $-.05(.12)$ \\
\hline \multicolumn{9}{|l|}{ equivalent } \\
\hline Negative & $.12(.22)$ & $-.05(.08)$ & $-.16(.22)$ & $-.03(.10)$ & $.13(.12)$ & $.09(.07)$ & $.05(.20)$ & $.13(.13)$ \\
\hline \multicolumn{9}{|l|}{ affectivity } \\
\hline Positive & $.15(.16)$ & $.02(.14)$ & $.07(.16)$ & $.13(.13)$ & $-.04(.08)$ & $.03(.08)$ & $.11(.14)$ & $-.26(.15)$ \\
\hline \multicolumn{9}{|l|}{ affectivity } \\
\hline Work & $.01(.01)$ & $.001(.01)$ & $.01(.01)$ & $-.018(.01)$ & $.000(.01)$ & $-.01(.01)$ & $-.003(.01)$ & $.01(.01)$ \\
\hline
\end{tabular}


Running head: AFFECTIVE CHANGES IN INACTIVE EMPLOYEES

\begin{tabular}{|c|c|c|c|c|c|c|c|c|}
\hline \multirow[t]{5}{*}{ Workload } & $.01(.04)$ & $.004(.05)$ & $.09(.04)^{*}$ & $.22(.05)^{* *}$ & $-.11(.03)^{* *}$ & $-.05(.04)$ & $.01(.04)$ & $-.01(.07)$ \\
\hline & \multicolumn{8}{|c|}{$-2 * \log \mathrm{L}$} \\
\hline & 395.78 & 246.43 & 457.27 & 283.00 & 246.79 & 180.24 & 464.09 & 352.89 \\
\hline & \multicolumn{8}{|c|}{$\Delta-2 * \log L$ compared to unconditional model } \\
\hline & $30.89 * *$ & $26.07 * *$ & $21.67 * *$ & $41.75 * *$ & $36.01 * *$ & 12.24 & 10.53 & 6.06 \\
\hline
\end{tabular}

Notes. IT $=$ Immediate Treatment condition $(n=26) ; \mathrm{DT}=$ Delayed Treatment condition $(n=30) .{ }^{*}=p<.05 ; * *=p<.01$.

The percentages indicate the reduction in the within-person variability of the intercept due to the inclusion of the day variable (pseudo- $R^{2}$ for level 2; pseudo- $R^{2}$ for level 1). In all models, the variance of level 1 and level 2 residual errors were significantly different from zero. 